\title{
The Influence of Slope Shape on Slope Seismic Stability
}

\author{
Zhaopeng Zhang, ${ }^{1, *}$, Jingshan $\mathrm{Bo}^{1,2}$ and Feng Qiao ${ }^{1}$ \\ ${ }^{1}$ Institute of Engineering Mechanics, China Earthquake Administration, Key Laboratory of Earthquake Engineering and \\ Engineering Vibration, China Earthquake Administration, Harbin, China \\ ${ }^{2}$ Institute of Disaster Prevention, Sanhe, China. \\ ${ }^{*}$ Corresponding author
}

\begin{abstract}
This paper mainly uses numerical simulation software to study the influence of different slope shapes on the seismic stability of slopes. With building three different numerical models, the safety factor is used to compare the stability of convex, concave and linear slopes under earthquake. The calculation results show that there are great differences in the seismic responses of slopes with different slope shapes.
\end{abstract}

Keywords-numerical simulation; slope stability; slope shape

\section{INTRODUCTION}

There are many factors that affect the stability of the slope, for example, the macroscopic factors include geological structure, topography and geomorphologyand hydro geological conditions; the microcosmic includes mineral composition, pore water and so on. However, the most intuitive factor is still the geometry of the slope. The control indicators of the slope geometry mainly include the slope height, slope angel and slope shape, the research work on the impact of the first two indicators on the stability of the slope has been relatively mature. Therefore, this paper focuses on the effect of slope shape on the seismic stability of slopes.

In reality, the shape of the slope is varied due to the change of the vertical and horizontal directions of the slope. After ignoring the effect of vertical profile morphology, according to the shape of the undulation, the shape of the slope can be divided into three basic types of convex, concave and linear, and the combination of the three basic slopes. However, in the past, people mainly focused on the influence of slope shape on the dynamic response of the slope, and the stability of the slope was not discussed.

In view of this, the Geo-studio software is used in this paper to study the influence of different slope shapes on the seismic stability of slopes. By establishing three numerical models, the safety factor is used as the evaluation indicator to compare and analyze the stability of various slope models, and the calculation results are discussed and summarized.

\section{MODE AND SEISMIC WAVE}

\section{A. Numerical Model}

In order to fully reflect the influence of slope shape on the seismic response of slopes, the models are set to homogeneous slopes. In addition to the shape of the slope, the model geometry and material parameters are exactly the same. As shown in FIGURE I and TABLE I, the change points of the convex and concave slopes are set at half of the height.

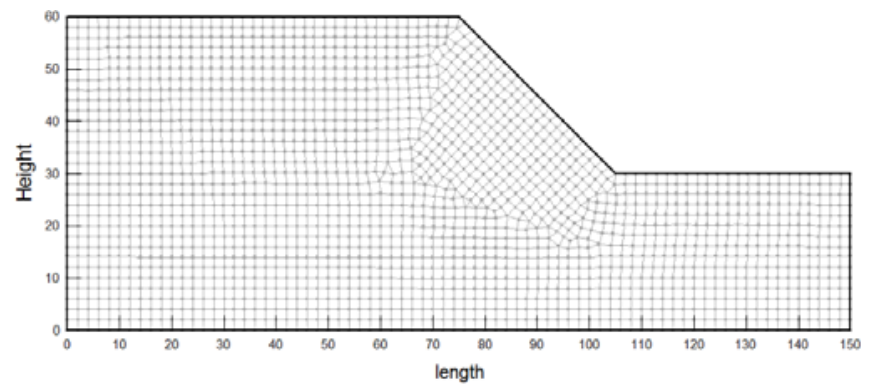

(a) Linear shape

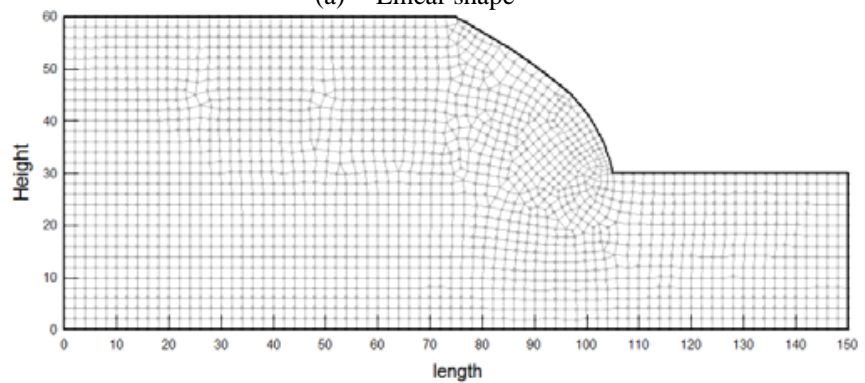

(b) Convex shape

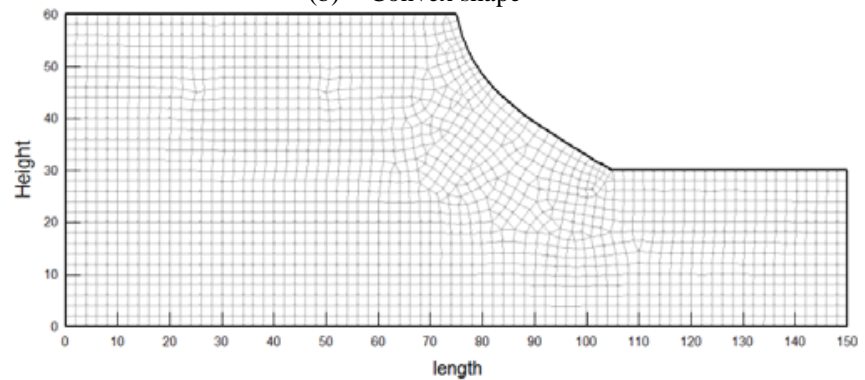

(c) Concave shape

FIGURE I. MESH SKETCH OF THE HOMOGENEOUS SLOPE MODEL (UNIT: M) 
TABLE I. CALCULATION PARAMETERS OF A HOMOGENEOUS SLOPE

\begin{tabular}{|c|c|c|}
\hline $\begin{array}{c}\text { Young's modulus } \\
\text { E/MPa }\end{array}$ & $\begin{array}{c}\text { Poisson's ratio } \\
\mu\end{array}$ & $\begin{array}{c}\text { Cohesion } \\
C / \mathrm{kPa}\end{array}$ \\
\hline 10 & 0.3 & 32 \\
\hline $\begin{array}{c}\text { Friction angle } \\
\varphi /\left(^{\circ}\right)\end{array}$ & $\begin{array}{c}\text { Unit weight } \\
\gamma /\left(\mathrm{kN} \cdot \mathrm{m}^{-3}\right)\end{array}$ & $\begin{array}{c}\text { Dilatancy angle } \\
\psi^{\prime} /\left(^{\circ}\right)\end{array}$ \\
\hline 26 & 20 & 0 \\
\hline
\end{tabular}

\section{B. Seismic Wave}

In this paper, the Kobe wave (N-S) is chosen as the input wave. The amplitude of the seismic wave is adjusted to $0.1 \mathrm{~g}$, $0.2 \mathrm{~g}, 0.3 \mathrm{~g}$ and $0.4 \mathrm{~g}$, and the holding time is $15 \mathrm{~s}$. After the baseline corrected, the acceleration duration curve with a peak acceleration of $0.3 \mathrm{~g}$ is shown in FIGURE II. The Kobe wave is input horizontally from the bottom of the model.

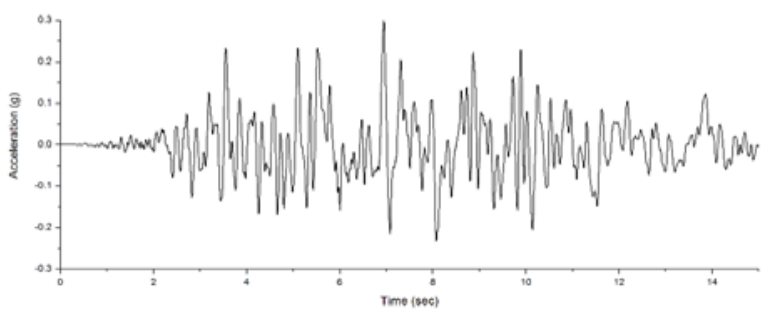

FIGURE II. BASELINE CORRECTED KOBE ACCELEROGRAM SCALED TO A PEAK ACCELERATION OF 0.3G

\section{EFFEct OF SLOPE Shape ON SEISMic Stability of SLOPE}

\section{Calculation Results of Pseudo-static Method}

TABLE II shows the minimum safety factor for each slope shape under different amplitude conditions. By comparison, it can be seen that when using the pseudo-static method to calculate the slope safety factor, the safety factor of the concave slope is the biggest, and the safety factor of the convex slope is the smallest. Under the same amplitude of the seismic wave, the sequence of slope stability of different slope shapes from high to low is concave shape, linear shape, and convex shape.

TABLE II. SAFETY SUMMARY OF PSEUDO-STATIC METHOD

\begin{tabular}{|c|c|c|c|c|}
\hline amplitude & method & linear & convex & concave \\
\hline \multirow{3}{*}{$0.1 \mathrm{~g}$} & Bishop method & 1.09 & 1.02 & 1.15 \\
\cline { 2 - 5 } & Janbu method & 1.04 & 1.01 & 1.08 \\
\cline { 2 - 5 } & Spencer method & 1.10 & 1.06 & 1.17 \\
\hline \multirow{3}{*}{$0.15 \mathrm{~g}$} & Bishop method & 1.07 & 1.01 & 1.14 \\
\cline { 2 - 5 } & Janbu method & 1.02 & 0.98 & 1.06 \\
\cline { 2 - 5 } & Spencer method & 1.07 & 1.04 & 1.15 \\
\hline \multirow{3}{*}{$0.2 \mathrm{~g}$} & Bishop method & 1.07 & 0.99 & 1.12 \\
\cline { 2 - 5 } & Janbu method & 1.01 & 0.97 & 1.05 \\
\cline { 2 - 5 } & Spencer method & 1.06 & 1.03 & 1.13 \\
\hline \multirow{3}{*}{$0.3 \mathrm{~g}$} & Bishop method & 1.03 & 0.97 & 1.10 \\
\cline { 2 - 5 } & Janbu method & 0.98 & 0.94 & 1.02 \\
\cline { 2 - 5 } & Spencer method & 1.03 & 1.00 & 1.10 \\
\hline & Bishop method & 1.00 & 0.95 & 1.07 \\
\cline { 2 - 5 } & Janbu method & 0.95 & 0.93 & 1.00 \\
\cline { 2 - 5 } & Spencer method & 1.02 & 0.97 & 1.07 \\
\hline
\end{tabular}

\section{Calculation Results of Time-history Method}

FIGURE III shows the time-history of the safety factor under different amplitude of Kobe waves, it can be seen from the figure that under the static conditions (time is 0 ), the sequence of safety factor corresponding to the shape of the three models from high to low is concave, linear, convex, it indicates that the stability of the concave slope is more stable under static conditions.

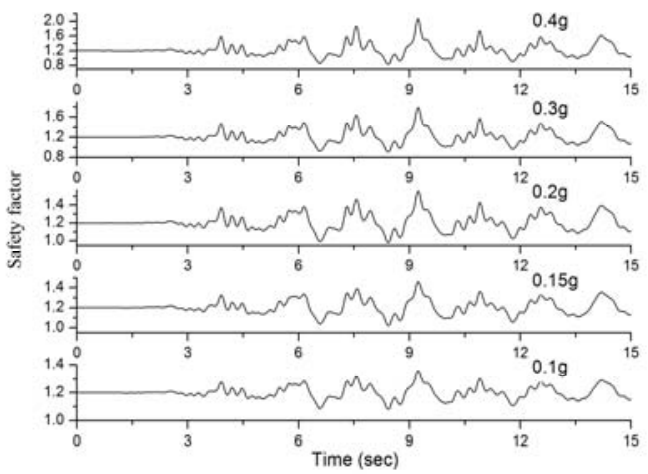

(a) Linear shape

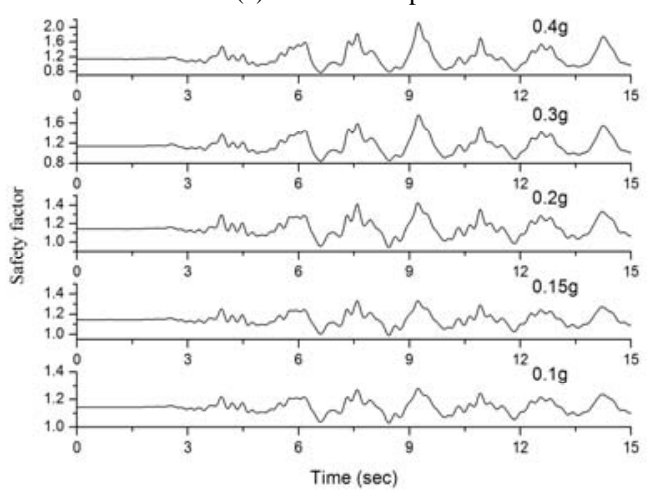

(b) Convex shape

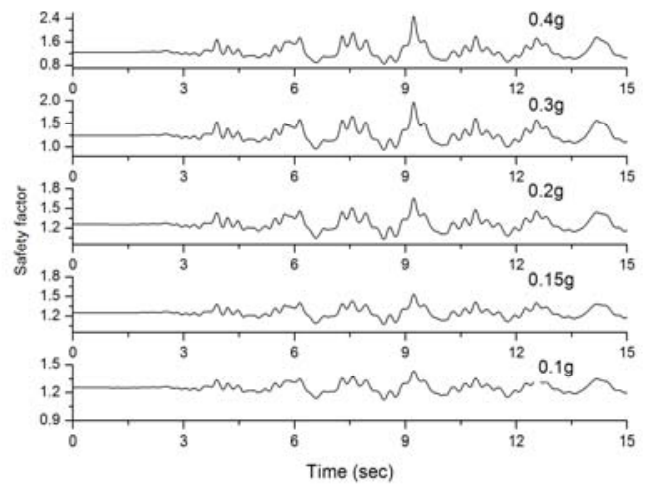

(c) Concave shape

FIGURE III. TIME HISTORY OF SLOPE DYNAMIC SAFETY FACTOR

The minimum safety factor [1], average safety factor [2], the minimum mean safety factor [3], and reliability safety factor [4] corresponding to the time-history of the safety factor of each slope shape are summarized in TABLE 3, it can be seen from the TABLE: 
TABLE III. THE SUMMARY TABLE OF SAFETY FACTOR

\begin{tabular}{|c|c|c|c|c|}
\hline amplitude & method & linear & $\begin{array}{c}\text { Conve } \\
x\end{array}$ & $\begin{array}{c}\text { concav } \\
e\end{array}$ \\
\hline \multicolumn{5}{|l|}{$0.1 \mathrm{~g}$} \\
\hline & Minimum safety factor & 1.08 & 1.03 & 1.12 \\
\hline & Average safety factor & 1.20 & 1.15 & 1.25 \\
\hline & Minimum mean safety factor & 1.12 & 1.06 & 1.17 \\
\hline & Reliability safety factor & 1.09 & 1.04 & 1.14 \\
\hline \multicolumn{5}{|l|}{$0.15 \mathrm{~g}$} \\
\hline & Minimum safety factor & 1.02 & 0.99 & 1.07 \\
\hline & Average safety factor & 1.21 & 1.15 & 1.26 \\
\hline & Minimum mean safety factor & 1.08 & 1.04 & 1.13 \\
\hline & Reliability safety factor & 1.05 & 1.01 & 1.09 \\
\hline \multicolumn{5}{|l|}{$0.2 \mathrm{~g}$} \\
\hline & Minimum safety factor & 0.99 & 0.94 & 1.03 \\
\hline & Average safety factor & 1.21 & 1.15 & 1.26 \\
\hline & Minimum mean safety factor & 1.06 & 1.01 & 1.11 \\
\hline & Reliability safety factor & 1.01 & 0.96 & 1.05 \\
\hline \multicolumn{5}{|l|}{$0.3 \mathrm{~g}$} \\
\hline & Minimum safety factor & 0.91 & 0.85 & 0.94 \\
\hline & Average safety factor & 1.22 & 1.17 & 1.27 \\
\hline & Minimum mean safety factor & 1.01 & 0.95 & 1.05 \\
\hline & Reliability safety factor & 0.94 & 0.86 & 0.97 \\
\hline \multicolumn{5}{|c|}{ 1. } \\
\hline & Minimum safety factor & 0.84 & 0.78 & 0.86 \\
\hline & Average safety factor & 1.23 & 1.19 & 1.29 \\
\hline & Minimum mean safety factor & 0.97 & 0.90 & 0.99 \\
\hline & Reliability safety factor & 0.88 & 0.80 & 0.90 \\
\hline
\end{tabular}

- The sequence of slope stability of different slope shapes from high to low is concave, linear, convex, which is consistent with the results of pseudo-static method.

- The minimum safety factor, the minimum mean safety factor, and reliability safety factor all decrease with the increase of input seismic wave amplitude, it indicates that the stability of the slope gradually decreases with the increase of the ground motion intensity, and only the average safety factor varies with the amplitude, which shows that using the average safety factor as an evaluation index may overestimate the stability of the slope.

\section{CONCLUSION}

In this paper, pseudo-static method and time-history method are used to calculate the influence of slope shape on the seismic response of slopes. By establishing two-dimensional calculation models for the shape of slopes and using safety factor as evaluation indicators, the shape of the slopes under different intensity ground motions is analyzed. It can reach the following conclusions:

- (1) The stability of the same slope (except the average safety factor as the evaluation index) gradually decreases with the increase of input ground motion intensity, which is consistent with the actual results.

- (2) Under the same ground motion intensity, the stability of the concave slope is best and the stability of the convex slope is the worst

\section{REFERENCES}

[1] BO Jing-shan, XU Guo-dong, JING Li-ping. Seismic response and dynamic stability analysis of soil slopes. Earthquake Engineering and Engineering Vibration, Vol. 11(2001) No. 2, p.116-120.

[2] WU Zhao-ying, BO Jing-shan, LIU Hong-shuai, et al. Amethod for evaluating dynamic safety factor rock slopeseismic stability analysis. Journal of DisasterPrevention and Mitigation Engineering, Vol 24(2003) No.3, p.237-241.

[3] LIU Han-long, FEI Kang, GAO Yu-feng. Time history analysis method of slope seismic stability. Rock and Soil Mechanics, Vol 24(2003) No.4, p.553-556.

[4] LIU Hong-shuai. Study on Analysis Method of Rock Slope Seismic Stability. Institute of Engineering Mechanics, China Earthquake Administration, China (2005). 